\title{
Cognitive Impairment in Multiple Sclerosis
}

\author{
Anastasiya G. Trenova ${ }^{1}$, Georgi S. Slavov ${ }^{1}$, Maria G. Manova ${ }^{1}$, Jana B. Aksentieva ${ }^{1}$, \\ Lyuba D. Miteva², Spaska A. Stanilova ${ }^{2}$ \\ ${ }^{1}$ Department of Neurology, Faculty of Medicine, Medical University of Plovdiv, Plovdiv, Bulgaria \\ ${ }^{2}$ Department of Molecular Biology, Immunology and Medical Genetics, Trakia University, Stara Zagora, Bulgaria
}

\author{
Correspondence: A. Trenova, \\ Department of Neurology, \\ Faculty of Medicine, Medical \\ University of Plovdiv, Plovdiv, 15A \\ Vassil Aprilov Blvd., 4002, Plovdiv, \\ Bulgaria \\ E-mail: atrenova@yahoo.com \\ Tel: +35932602279
}

Received: 15 April 2016

Accepted: 20 June 2016

Published Online: 13 Aug 2016

Published: 30 Sept 2016

Key words: multiple sclerosis, cognitive impairment, neuropsychological tests

Citation: Trenova AG, Slavov GS, Manova MG, Aksentieva JB, Miteva LD, Stanilova SA. Cognitive impairment in multiple sclerosis. Folia Medica 2016;58(3);157-163, doi: 10.1515/folmed-2016-0029
Multiple sclerosis (MS) is a socially significant immune-mediated disease, characterized by demyelination, axonal transection and oligodendropathy in the central nervous system. Inflammatory demyelination and neurodegeneration lead to brain atrophy and cognitive deficit in up to $75 \%$ of the patients. Cognitive dysfunctions impact significantly patients' quality of life, independently from the course and phase of the disease.

The relationship between pathological brain findings and cognitive impairment is a subject of intensive research.

Summarizing recent data about prevalence, clinical specificity and treatment of cognitive disorders in MS, this review aims to motivate the necessity of early diagnosis and complex therapeutic approach to these disturbances in order to reduce the social burden of the disease.

\section{INTRODUCTION}

Multiple sclerosis (MS) is a socially significant disease with unclear multifactorial etiology. One or more environmental factors unlock the disease in genetically predisposed individuals. Immunemediated processes in the peripheral blood and in the central nervous system (CNS) produce disseminated foci of inflammatory demyelination mainly in white matter, but recent studies found pathomorphological disorders also in gray matter of the thalamus, hippocampus, cerebral cortex. The immune-mediated destruction of myelin is accompanied by chronic progressive degeneration within the CNS - the cause of tissue damage and brain atrophy in the later stages of disease evolution. ${ }^{1}$ Pathomorphological changes are expressed clinically with various combinations of neurological symptoms - motor, sensory, visual, bowel/bladder dysfunctions, and a significant proportion of patients have cognitive impairments. Although neuropsychological manifestations of MS have been described decades ago by Jean-Martin Charcot, they have recently been a subject of scientific interest because of their high incidence, occurrence in the early stages of the disease and great importance for professional realization, personal relationships and quality of life of MS patients.

\section{CHARACTERISTICS OF MS-RELATED COGNI- TIVE DEFICIT}

A review of the literature shows variation in the prevalence rate of cognitive disorders - from $40 \%$ to $65 \%-75 \% .^{2-6,9}$ Differences in the study design, characteristics of the sample, neuropsychological tests used for diagnosis, heterogeneity in the type and severity of the disease are some of the factors determining these discrepancies. ${ }^{10}$ A cross-sectional multicenter survey of Cáceres et al. (2011) has shown a prevalence rate of $43.2 \%$ for cognitive impairments among patients with MS in Argentina, and similar research of Papathanasiou et al. (2014) 
in the Greek MS population has registered cognitive deficits in 53.75\%. ${ }^{4,5}$ A study in Bulgaria by Genov, (2003) has found cognitive disturbances in $74.7 \%$ of the observed contingent distributed according to the severity of cognitive dysfunction as follows: mild - $26.7 \%$, moderate $-25.3 \%$, severe $-12.7 \%{ }^{6}$

The prevalence of cognitive disorders in MS varies with the type and stage of the disease - it is the highest for the secondary progressive MS and even can get as high as $80 \%$ as reported by Papathanasiou et al. (2014). ${ }^{5,9}$ It has been stated that $7 \%$ to $29 \%$ of the patients with primary progressive MS develop cognitive deficit. ${ }^{10}$ Cognitive dysfunction has been also found in the early stages of the disease (duration of less than 5 years). According to various authors, the frequency is in the range of 20 to $45 \%$ and is observed even in patients with a clinically isolated syndrome. ${ }^{711-13}$ According to the study by Achiron and Barak (2003), 95\% of the studied patients with possible MS had an abnormal score in at least one neuropsychological test. ${ }^{14}$

Cognitive dysfunctions in MS patients have been found to be correlated with a number of other factors besides the type and duration of the disease. Studies have shown that race, and possibly other genetic factors influence the clinical presentation of the disease, including the effect on the cognitive functions. Weinstock-Guttman et al. (2003) have found that cognitive deficit had earlier onset in African Americans with MS than in Caucasian patients. ${ }^{15}$ Similar data were reported in children with MS. ${ }^{16}$ On the other hand, the patients' age and the age at disease onset are factors determining the variability of cognitive impairment. ${ }^{17}$ Gender differences have been established in the severity of clinical signs and the course of the MS. In men, the course of the disease is more severe, with more rapid progression of disability than in women. Similarly, the prevalence and severity of cognitive impairment are more pronounced in male patients. ${ }^{7}$

Intelligence and education, as factors determining the cognitive reserve, also affect the appearance of cognitive deficit. A five-year longitudinal study has found significant cognitive decline in patients with low baseline cognitive reserve, unlike those with higher intelligence and education, in whom no cognitive deficits were detected up to the end of the observational period. ${ }^{18}$

The first Bulgarian longitudinal study of cognitive functioning in MS conducted by Genov K., (2015) has found an association between different cognitive domains and age, disease duration, EDSS, overall intelligence. Similar to previous reports of other researchers Bulgarian patients with primary progressive and secondary progressive MS have shown more severe cognitive decline. An important finding of the same study is the predictive value of lower results on neuropsychological tests in early relapsing-remitting MS for progression of the neurological deficit assessed by EDSS. ${ }^{19}$

Presence of depression, chronic fatigue and the overall physical disability affect the cognitive abilities of MS patients, but a tight causal relationship between the severity of neurological and cognitive deficit has not been proven. ${ }^{19,20}$

Recently, the correlation between the localization and intensity of pathomorphological changes and the severity of cognitive deficit has been extensively studied. Modern MRI techniques demonstrate high sensitivity in visualizing pathomorphological damage that is credible perspective for research in this aspect. ${ }^{17,21}$ Patients with impaired cognition have been found to have a significantly higher total $\mathrm{T} 1$ and $\mathrm{T} 2$ lesion load compared to cognitively preserved subjects. A number of observations have reported correlation between cognitive disorders and localization of the lesions in the white or gray matter, but the link with the total lesion load in the white brain matter is more pronounced in comparison with the lesion volume in gray cortical/ subcortical structures..$^{22,23}$ The dependence of poor results in neuropsychological tests with frequent location of MS lesions in forceps major and splenium corporis callosi established by Rossi et al. (2012) supports the hypothesis of functional disconnection between key areas in cortical gray matter as a primary mechanism underlying the cognitive deficit in MS. ${ }^{23}$ A study combining two different MRI techniques has shown that both intracortical lesions and mixed lesions play a more significant role than juxtacortical lesions and measures of atrophy in cognitive impairment. ${ }^{24}$

The total brain atrophy and atrophy of cerebral cortex and subcortical gray nuclei like the thalamus, putamen, hippocampus, amygdala, nucleus accumbes, are proven to be associated with cognitive impairment in MS. ${ }^{17,23}$

Over recent years many studies started measuring abnormalities in normally appearing grey matter by using various quantitative MRI techniques and their correlations with cognitive functions in MS. Cortical magnetization transfer (MT) ratio has been the only MRI parameter associated with impaired mental processing speed in patient with clinically 
isolated syndrome. ${ }^{25} \mathrm{~A} 13$-year follow-up study have established grey matter MT-ratio as the only MRI predictor of global cognitive impairment, supporting the notion that grey matter plays a major role in the long-term development of cognitive decline. ${ }^{26}$

Studies have found an association between changes in certain areas of gray matter and deficit in a specific cognitive domain. ${ }^{17} \mathrm{~A}$ significant association between memory, deep gray matter structures, and cortical thinning of the frontal and temporal gyrus was demonstrated by Pellicano et al. (2013). ${ }^{27}$

Cognitive disorders in MS show heterogeneity in their type and severity, but are similar to those of subcortical dementias. Despite considerable individual variations, the most frequently affected domains are attention, executive functions, information processing, visuo-spatial perception and memory and working memory. ${ }^{2,3}$

MS patients perform attention-demanding tasks slower, with more inaccuracies and omissions. ${ }^{20}$ They have difficulty in sustaining attention for a long period of time as well as in divided attention, but a so-called simple attention (i.e., repetition of numbers) is usually unaffected. ${ }^{3,28}$ The ability for dividing and switching attention between different tasks is predominantly affected and shows decreased cognitive plasticity in MS. ${ }^{19}$

Memory deficit is presented primarily by impaired learning of new information, and in lesser extent by difficulty in recall and recognition. MS patients with cognitive deficit need more repetitions to learn the predetermined amount of information. Unlike Alzheimer dementia, accelerated forgetfulness and loss of memories of people and events from the past is not typical for MS-driven cognitive decline. According to some researchers, the disturbed encoding is a consequence of low information processing speed and impaired executive functions. Attention deficit, with difficulty in ignoring irrelevant stimuli, also contributes to impaired learning. ${ }^{3,29}$

Efficiency of information processing depends on the ability of the brain to retain and manipulate it for a short period of time as well as the speed with which this process is carried out. The reduced information processing speed is one of the most common cognitive impairments in MS and predicts long-time development of cognitive decline. Studies have established a positive correlation between the slow information processing speed and the memory deficit. ${ }^{30,31}$ The disturbances in working memory and information processing speed are interrelated - the deficit in both spheres becomes more pronounced with increased requirements for working memory. The slowed information processing speed also affects the performance of the attention-demanding tasks. ${ }^{32}$

Executive functions, including abstract and conceptual thinking, verbal fluency, ability to plan and organize, are affected in cognitively impaired MS patients. According to Drew et al. (2008) 17\% of patients have difficulties in multiple executive skills. ${ }^{33}$ Verbal fluency tests, assessing the spontaneous production of words at search-restricting conditions (a certain initial letter or from one semantic category), show deficits in phonetic and semantic fluency, frequent perseverative errors and are a sensitive method for detecting cognitive impairment in MS.

The deficit of visuoperceptual functions is typical for MS cognitive impairment. These functions include not only the recognition of visual stimuli, but also the ability for accurate determination of their characteristics. Despite the limited number of studies on the incidence of these disorders in MS, it is assumed that about one quarter of the patients have deficits in the visuo-spatial domain. Disturbances in visuoperceptual functions have been detected not only in MS patients diagnosed with cognitive decline, but also in those determined as cognitively preserved. Abnormalities in the afferent visual pathway (optic neuritis) and the primary visual cortex in the occipital lobe may further aggravate the visuoperceptual defect. ${ }^{20,34}$

Usually, storage of learned information, semantic knowledge and intelligence are not impaired, but in 10 to $15 \%$ of MS patients multiple cognitive domains are affected leading to the so called MSassociated dementia. ${ }^{18}$

\section{DIAGNOSTIC POSSIBILITIES}

The diagnosis of cognitive dysfunction in patients with MS and determination of its type and severity is crucial for establishing a proper and comprehensive treatment, rehabilitation and social adaptation of those individuals. The assessment of various indicators - continuing employment, independence in daily activities, educational level provides primary information about the presence of cognitive impairment. For this purpose different questionnaires directed towards the patients or their relatives have been developed. They allow screening of the cases that require further cognitive assessment. For a more precise examination of cognitive functions specific neuropsychological tests are used. They enable the 
detection, identification of the type and severity of cognitive impairment, and allow long-term followup. The neuropsychological examination can vary from a short screening test to a detailed evaluation of overall cognitive functioning of a patient. Neuropsychological testing in routine clinical practice occupies an intermediate position, focusing on evaluation of MS-related cognitive dysfunctions.

In 2001, an expert group of neurologists and neurophysiologists developed and introduced a battery of psychometric tests to study cognitive functions in MS that is highly consistent with the specifics of the pathological process of the disease. The battery known as MACFIMS (Minimal Assessment of Cognitive Function in MS) includes 7 tests that assess the information processing speed, working memory, the ability to learn and recall new information, visuospatial perception and higher executive functions. ${ }^{35}$ The battery, including Trail Making Test (TMT), Stroop Colour-Word Tests (SCWT), Verbal Fluency Test (VFT), Digit Span Forward (DSF), Paced Auditory Serial Additional Test (PASAT) Symbol Digit Modality Test (SDMT) and Raven Progressive Matrices is very sensitive for early diagnosis of cognitive deficit as well as for a longitudinal follow-up. ${ }^{19}$ However, a disadvantage of such batteries is the long time for examination, which makes them unpopular in the daily clinical practice and increases the chance for higher cognitive fatigability of these patients to influence the final results. The screening batteries used for the detection of patients at risk with respect to cognitive dysfunction, who need more thorough neuropsychological study and treatment, require considerably shorter time and are more easily applicable in everyday clinical practice. There are different variants of such tests: Brief Repeatable Battery of Neuropsychological Test (BRBNT), Repeatable Battery for Assessment of Neuropsychological Status (RBANS), Screening Examination for Cognitive Impairment (SEFCI), Neuropsychological Screening Battery for MS Status (NPSBMS), Brief International Cognitive Assessment for MS (BICAMS). ${ }^{36-39}$ They include tests focusing on learning and information processing speed.

Parmenter et al. (2007) established the good predictive value of SDMT administered alone. The test assesses primarily visuospatial cognitive domain and working memory. The study has shown that the effectiveness of SDMT as a screening tool is approximately equal to that of MACFIMS, as a score of 55 or less adequately categorizes $72 \%$ of patients with cognitive deficit. ${ }^{40}$ The test has shown particular sensitivity to the cognitive changes in MS, as well as reliability in quantitative tracking of changes for an extended period of time. ${ }^{11,41}$ This data, along with the short time of administration, makes this test a preferred tool both in clinical trials and routine clinical practice. ${ }^{42}$ The significant value of this test in cognitive assessment and monitoring of MS patients has been confirmed by the longitudinal study of Genov (2015). ${ }^{19}$

\section{SOCIAL ASPECTS OF COGNITIVE IMPAIR- MENT}

Cognitive impairment in MS patients is closely related to their overall functional status. The presence of cognitive deficit hampers normal daily activities such as shopping, household activities, use of public transportation, driving, and has a significant effect on professional employment and payment, and on interpersonal relationships and social adaptation of these individuals. Such problems are caused most often by the cognitive deficit in learning new information and the executive dysfunction, but the reduced information processing speed is also known to affect considerably the ability of these patients for adequate functioning in everyday life. ${ }^{43}$ The deficit in verbal memory, executive functioning and information processing speed has predictive value with respect to professional status even taking into account other related factors such as gender, age, education, course of the disease and the like. Studies show that 40 to $80 \%$ of MS patients are unemployed and cognitive disorders are an important factor in the high rate of unemployment among people with this disease. ${ }^{44}$ The negative effect of cognitive deficits on the listed areas of daily activity results in reduction of overall quality of life of patients with MS. ${ }^{45}$ Physical disability is a determining factor in the performance of daily activities, but cannot account for all the difficulties that these patients experience in solving tasks requiring significant cognitive capacity.

\section{THERAPEUTIC STRATEGIES}

Therapeutic approaches to cognitive impairment in MS are two main types - pharmacological and non-pharmacological. The pharmacological approach involves pathogenetically effective drugs that are capable in various degrees to suppress the immune-mediated demyelination and neurodegeneration in the CNS, and thus reduce the severity 
of clinical signs and progression of the disease. Clinical studies with acetylcholinesterase inhibitors (donepesil) provide promising results in some aspects of cognitive dysfunction, particularly in the memory disturbances of MS patients. ${ }^{46}$ Cognitive rehabilitation is a non-pharmacological approach that includes various compensatory strategies to improve day-to-day functional capacity of the patients and therapeutic activities aimed at restoration of the affected cognitive functions. Regardless of the contradictory results about the benefits of these methods, some experts recommend their use according to the individual characteristics and needs of each patient. ${ }^{47}$

In conclusion, cognitive impairment can appear at any stage of the disease in up to $75 \%$ of patients with MS and significantly affects daily, professional and social functioning. The cognitive dysfunction is relatively independent from the physical disability, but the severity of both physical and cognitive deficit increases with disease progression. This fact requires precise assessment and monitoring of cognitive impairment in order to implement adequate therapeutic methods and to reduce the adverse effect on the quality of life of MS patients.

\section{ACKNOWLEDGEMENTS}

This article is published in the Folia Medica as part of research project \#NO-02/2014 of the Medical University in Plovdiv entitled "Functional gene polymorphisms of cytokines and cognitive impairment in multiple sclerosis".

\section{REFERENCES}

1. Lassmann H. What drives disease in multiple sclerosis: Inflammation or neurodegeneration? Clin Exp Neuroimmunol 2010;1:2-11.

2. Hoffmann S, Tittgemeyerb M, Yves von Cramon D. Cognitive impairment in multiple sclerosis. Curr Opin Neurol 2007;20:275-80.

3. Chiaravalloti ND, DeLuca J. Cognitive impairment in multiple sclerosis. Lancet Neurol 2008;7:1139-51.

4. Cáceres F, Vanotti S, Rao S, et the RECONEM Workgroup (2011). Epidemiological characteristics of cognitive impairment of multiple sclerosis patients in a Latin American country. J Clin Exp Neuropsychol 2011;33(10):1094-98.

5. Papathanasiou A, Messinis L, Georgiou VL, Papathanasopoulos P. Cognitive Impairment in Relapsing Remitting and Secondary Progressive Multiple Sclerosis Patients: Efficacy of a Computerized Cognitive
Screening Battery. ISRN Neurol 2014:151379. doi: 10.1155/2014/151379.

6. Genov K. Changes of cognitive functions in patients with multiple sclerosis. (Clinical-psychological study). [Dissertation] Sofia, Academy of Military Medical Science, 2003.

7. Sandi D, Biernacki T, Szekeres D, et al. The prevalence of cognitive impairment among Hungarian patients with relapsing-remitting multiple sclerosis and clinically isolated syndrome. International Journal of Clinical Neurosciences and Mental Health 2016; 3(1):P12

8. Fischer M, Kunkel A, Bublak P, et al. How reliable is the classification of cognitive impairment across different criteria in early and late stages of multiple sclerosis? J Neurol Sci 2014;343(1-2):91-9.

9. Amato MP, Langdon D, Montalban X, et al. Treatment of cognitive impairment in multiple sclerosis: position paper. J Neurol 2013;260(6):1452-68.

10. Camp SJ, Stevenson VL, Thompson AJ, et al. A longitudinal study of cognition in primary progressive multiple sclerosis. Brain 2005;128(12):2891-8.

11. Amato MP, Portaccio E, Goretti B, et al. TuSCIMS Study Group. Relevance of cognitive deterioration in early relapsing-remitting MS: a 3-year follow-up study. Mult Scler 2010;16(12):1474-82.

12.Deloire MS, Salort E, Bonnet M, et al. Cognitive impairment as marker of diffuse brain abnormalities in early relapsing remitting multiple sclerosis. J Neurol Neurosurg Psychiatry 2005;76(4):519-26.

13. Kiraç LB, Ekmekçi Ö, Nur Yüceyar N, Kocaman AS. Assessment of Early Cognitive Impairment in Patients with Clinically Isolated Syndromes and Multiple Sclerosis. Behav Neurol 2014:637694, doi. org/10.1155/2014/637694.

14. Achiron A, Barak Y. Cognitive impairment in probable multiple sclerosis. J Neurol Neurosurg Psychiatry 2003;74(4):443-6.

15. Weinstock-Guttman B, Jacobs LD, Brownscheidle CM, et al, New York State Multiple Sclerosis Consortium. Multiple sclerosis characteristics in African-American patients in the New York State Multiple Sclerosis Consortium. Mult Scler 2003;9(3):293-98.

16. Ross KA, Schwebel DC, Rinker J, Ness J, Ackerson J. Neurocognitive sequelae in African American and Caucasian children with multiple sclerosis. Neurology 2010;75(23):2097-102.

17. Horakova D, Kalincik T, Dusankova JB, Dolezal O. Clinical correlates of grey matter pathology in multiple sclerosis. BMC Neurol 2012;12:1-10.

18. Benedict RH, Morrow SA, Weinstock Guttman B, Cookfair D, Schretlen DJ. Cognitive reserve moderates decline in information processing speed in 
multiple sclerosis patients. J Int Neuropsychol Soc 2010;16(5):829-35.

19. Genov K. Factors affecting cognitive deterioration in patients with multiple sclerosis (Clinical-psychological study). [Dissertation] Sofia, Academy of Military Medical Science, 2015.

20. Grazioli E, Yeh A, Benedict R, et al. Cognitive Dysfunction in MS: Bridging the Gap Between Neurocognitive Deficits, Neuropsychological Batteries and MRI. Future Neurology 2008;3(1):49-59.

21. Messina S, Patti F. Gray Matters in Multiple Sclerosis: Cognitive Impairment and Structural MRI. Mult Scler Int 2014;2014:609694.

22.Papadopoulou A, Müller-Lenke N, Naegelin Y, et al. Contribution of cortical and white matter lesions to cognitive impairment in multiple sclerosis. Mult Scler 2013;19(10):1290-6.

23. Rossi F, Giorgio A, Battaglini M, et al. Relevance of brain lesion location to cognition in relapsing multiple sclerosis. PLoS ONE 2012;7(11):e44826. doi:10.1371/journal.pone.0044826.

24. Nelson F, Datta S, Garcia N, Rozario NL, Perez F, Cutter G, Narayana PA, Wolinsky JS. Intracortical lesions by $3 \mathrm{~T}$ magnetic resonance imaging and correlation with cognitive impairment in multiple sclerosis. Mult Scler 2011;17(9):1122-9.

25. Khalil M, Enzinger C, Langkammer C, et al. Cognitive impairment in relation to MRI metrics in patients with clinically isolated syndrome. Mult Scler 2011;17(2):173-80.

26. Filippi M, Preziosa P, Copetti M, et al. Gray matter damage predicts the accumulation of disability 13 years later in MS. Neurology 2013;81(20):1759-67.

27. Pellicano C, Kane RL, Gallo A, et al. Cognitive impairment and its relation to imaging measures in multiple sclerosis: a study using a computerized battery. J Neuroimaging 2013;23(3):445-52.

28. Macniven JA, Davis C, Ho MY, Bradshaw CM, Szabadi E, Constantinescu CS. Stroop performance in multiple sclerosis: information processing, selective attention, or executive functioning. J Int Neuropsychol Soc 2008;14:805-14.

29. Renell PG, Jensen F, Henry JD. Prospective memory in multiple sclerosis. J Int Neuropsychol Soc 2007;13:410-16.

30. Janculjak D, Mubrin A, Brinar V, Spilich G. Changes of attention and memory in a group of patients with multiple sclerosis. Clin Neurol Neurosurg 2002;104:221-27.

31. Lengenfelder J, Chiaravalloti ND, Ricker JH, DeLuca J. Deciphering components of impaired working memory in multiple sclerosis. Cognitive Behavior Neurol 2003;16:635-39.

32.Parmenter JL, Shucard JL, Schucard DW. Information processing deficits in multiple sclerosis: a matter of complexity. J Int Neuropsychol Soc 2007; 13:417-23.

33. Drew M, Tippett LJ, Starkey NJ, Isler RB. Executive dysfunction and cognitive impairment in a large community-based sample with multiple sclerosis form New Zealand: a descriptive study. Arch Clin Neuropsychol 2008;23:1-19.

34. Hickman SJ, Raoof N, McLean RJ, Gottlob I. Vision and multiple sclerosis. Mult Scler Rel Dis 2014;3:3-16.

35. Benedict RH, Fischer JS, Archibald CJ, et al. Minimal neuropsychological assessment of MS patients: a consensus approach. Clin Neuropsychol 2002;16(3):381-97.

36. Rao SM. The Cognitive Function Study Group of the National Multiple Sclerosis Society. In: A Manual for the Brief Repeatable Battery of Neuropsychological Tests in Multiple Sclerosis. Medical College of Wisconsin, WI, USA 1990.

37. Randolph C. Repeatable Battery for the Assessment of Neuropsychological Status. Psychological Corporation, TX, USA 1998.

38. Beatty WW, Paul RH, Wilbanks SL, Hames KA, Blanco CR, Goodkin DE. Identifying multiple sclerosis patients with mild or global cognitive impairment using the screening examination for cognitive impairment (SEFCI). Neurology 1995;45:718-23.

39. Benedict RH, Amato MP, Boringa J, et al. Brief International Cognitive Assessment for MS (BICAMS): international standards for validation. BMC Neurol 2012;12:55.

40.Parmenter BA, Weinstock-Guttman B, Garg N, Munschauer F, Benedict RH. Screening for cognitive impairment in multiple sclerosis using the Symbol digit Modalities Test. Mult Scler 2007;13(1):52-7.

41. Strober LB, Rao SM, Lee J-C, Fischer E, Rudick R. Cognitive impairment in multiple sclerosis: An 18-year follow-up study. Mult Scler Rel Dis 2014;3:473-81.

42. Van Schependom J, D'hooghe MB, Cleynhens K, D’hooge M, Haelewyck MC, De Keyser J, Nagels G. The Symbol Digit Modalities Test as sentinel test for cognitive impairment in multiple sclerosis. Eur J Neurol 2014;21(9):1219-25

43. Kalmar JH, Gaudino EA, Moore NB, Halper J, DeLuca J. The relationship between cognitive deficits and everyday functional activities in multiple sclerosis. Neuropsychology 2008;22:442-49.

44. Morrow SA, Drake A, Zivadinov R, Munschauer F, Weinstock-Guttman B, Benedict RH. Predicting loss of employment over three years in multiple sclerosis: clinically meaningful cognitive decline. Clin Neuropsychol 2010;24(7):1131-45.

45.Hoogs M, Kaur S, Smerbeck A, Weinstock-Guttman B, Benedict RH. Cognition and physical disability in 
predicting health-related quality of life in multiple sclerosis. Int J MS Care 2011;13(2):57-63.

46. Christodoulou C, MacAllister WS, McLinskey NA, Krupp LB. Treatment of cognitive impairment in multiple sclerosis: is the use of acetylcholinesterase inhibitors a viable option? CNS Drugs 2008;22:87-97.
47. Benedict RH, Ben-Zacharia A, Bednarik PA, et al; National Clinical Advisory Board of the National Multiple Sclerosis Society. Treatment Recommendations for Physicians: Assessment and Management of Cognitive Impairment in Multiple Sclerosis. Expert Opinion Paper 2008; New York, NY10017-32.

\title{
Когнитивные нарушения при множественном склерозе
}

\author{
Анастасия Г. Тренова ${ }^{1}$, Георги С. Славов ${ }^{1}$, Мария Г. Манова ${ }^{1}$, Яна Аксентиева ${ }^{1}$, \\ Люба Д. Митева'ㄹ, Спаска А. Станилова ${ }^{2}$ \\ ${ }^{1}$ Кафедра неврологии, Медицинский факультет, Пловдивский медицинский университет, Пловдив, Болгария \\ 2 Кафедра молекулярной биологии, иммунологии и медицинской генетики, Фракийский университет, Стара Загора, \\ Болгария
}

\section{Для корреспонденции: Анастасия Тренова, Кафедра неврологии, Медицинский факультет, Пловдивский медицинский университет, бул. Васила Априлова № 15A, Пловдив 4002, Болгария \\ E-mail: atrenova@yahoo.com \\ Тел.: +35932602279}

Дата получения: 15.04.2016 г. Дата приемки: 20.06.2016 г. Дата онлайн публикации: 13.08.2016 г.

Дата публикации: 30.09 .2016 г.

\section{Ключевые слова:}

множественный склероз, когнитивные нарушения, нейропсихологические исследования

Цитаты: Тренова А.Г., Славов Г.С., Манова М.Г., Аксентиева Я.В., Митева Л.Д., Станилова С.А. Когнитивные нарушения при множественном склерозе.

Журнал "Folia Medica" 2016;58(3);157-163,

doi: 10.1515/folmed-2016-0029
Множественный склероз (МС) - социально значимое иммуннообусловенное заболевание, характеризующееся демиелинизацией, аксональным перерывом и олигодендропатией в центральной нервной системе. Воспалительная демиелинизация и нейродегенерация влекут за собой атрофию мозга и когнитивный дефицит почти у 75\% пациентов. Когнитивные дисфункции оказывают серьезное влияние на качество жизни пациентов, независимо от хода и фазы заболевания.

Связь между патологическими находками в мозге и когнитивным нарушением является объектом интенсивного исследования.

В качестве обобщения последних данных о распространении, клинической специфичности и лечении когнитивных расстройств, настоящая статья ставит перед собой целью мотивировать необходимость в ранней диагностике и комплексном терапевтическом подходе к этим нарушениям, с целью снижения степени социальной тяжести заболевания. 